\title{
Mersin İlindeki Bir Otelin Soğutulması için Güneş Enerjisi Destekli Absorbsiyonlu Soğutma Sistemi Tasarımı ve Teorik Analizleri
}

\author{
Bengi GÖZMEN ŞANLI*, Elif TURNA DİLSEL \\ Mersin Üniversitesi, Mühendislik Fakültesi, Makine Mühendisliği Bölümü, Mersin
}

\begin{abstract}
$\ddot{\mathbf{O} z}$
$\mathrm{Bu}$ çalışmada, güneș enerjisi destekli tek etkili su-lityum bromür $\left(\mathrm{H}_{2} \mathrm{O}-\mathrm{LiBr}\right)$ karışıııı kullanan absorbsiyonlu bir soğutma sistemi kullanılarak Mersin ilinde bulunan 40 yataklı bir otelin soğutulması amaçlanmıştır. Beş aylık soğutma sezonu içerisinde hava sıcaklığının en yüksek olduğu Ağustos ayı verilerine göre tasarım gerçekleştirilmiştir. Öncelikle otelin soğutma yükü $84.6 \mathrm{~kW}$ olarak belirlenmiş̧ir. Otelin soğutma yükünü karşılamak amaciyla jeneratöre verilmesi gereken $181119.413 \mathrm{~kW}$ olarak hesaplanmış, bu 1sıyı karşılayabilmek için farklı tipte kollektörler (düz plakalı ve vakum tüplü) göz önüne alınarak gerekli kollektör yüzey alanı belirlenmiştir. Gerekli soğutma yükünün sağlanabilmesi için ihtiyaç duyulan vakum tüplü kollektör yüzey alanı $359.5 \mathrm{~m}^{2}$ olarak hesaplanmışken düz plakalı kollektör yüzey alanı $690.1 \mathrm{~m}^{2}$ olarak belirlenmiştir. Güneşten karşılanması gereken ısının vakum tüplü kollektör kullanılması durumunda gerekli olan kolektör yüzey alanının, düz plakalı kollektör kullanılması durumunda gereksinim duyulan kollektör yüzey alanından $330.6 \mathrm{~m}^{2}$ daha az olmasından dolayı \% 61.5 verime sahip vakum tüplü kollektör kullanımının daha uygun olduğu kanaatine varılmıştır
\end{abstract}

Anahtar kelimeler: Absorbsiyonlu Soğutma, Güneş Enerjisi, Güneş Kollektörü.

\section{Design and Theoretical Analysis of Solar Assisted Absorption Refrigeration System to Cool a Hotel in the City of Mersin}

\begin{abstract}
In this study, cooling of a hotel having 40 rooms in Mersin by using solar-assisted single effect absorption refrigeration machine, which uses water-lithium bromide $\left(\mathrm{H}_{2} \mathrm{O}-\mathrm{LiBr}\right)$ mixture, has been aimed. Design of the cooling machine has been carried out according to data of August the warmest month in the cooling season. The cooling load of hotel building and the heat given to generator have been calculated. To provide the heat given to generator which is used to supply hotel's cooling energy demand, required collector surface area has been determined by considering different types of collectors (flat plate and evacuated tube collectors). In order to obtain the cooling load requirements of the hotel, the required surface area for the evacuated tube collectors was calculated to be $359.5 \mathrm{~m}^{2}$ as it is found to be $690.1 \mathrm{~m}^{2}$ for the flat plate collectors. The difference between the required surface area of evacuated tube collectors and flat plate collectors was nearly $330.6 \mathrm{~m}^{2}$ and it has been understood that the usage of evacuated tube collectors is suitable for this cooling system.
\end{abstract}

Keywords: Absorption Refrigeration, Solar Energy, Solar collector.

\section{Giriş}

Günümüzde fosil yakıtlara alternatif olarak yenilenebilir enerji kaynakları büyük önem arz etmektedir. Yenilenebilir enerji kaynaklarının tercih edilmelerinin en önemli nedenleri dışa bağımlılıklarının olmaması ve sonsuz miktarda olmalarıdır. Yenilenebilir enerji kaynakları arasında güneş enerjisi temiz, çevreci olması yanında ülkemizin uzun güneşlenme sürelerine sahip olması nedeniyle üzerinde titizlikle çalışlan bir konu haline gelmiştir.

*Sorumlu yazar: bengigozmen@gmail.com

Geliş Tarihi: 22.05.2018, Kabul Tarihi: 07.09.2018 
Ülkemiz güneş kemeri adı verilen bölge içerisinde yer almaktadır [1] ve Güneydoğu Anadolu Bölgesi en fazla güneş alan bölge olup Akdeniz Bölgesi ikinci sırada yer almaktadır. Bu bölgelerde yaşam alanlarında isıl konforu sağlamak için soğutma işlemi ciddi bir ihtiyaç haline gelmiştir. Bu amaçla Fransız Ferdinand Carre tarafından bulunan, 1s1 enerjisi ile çalışan absorbsiyonlu soğutma sistemi yaz aylarında soğutma ihtiyacını karşılamak üzere yaygın olarak tercih edilmektedir [2]. Bu sistemler kullanılarak gerekli olan enerji ihtiyacı, soğutma giderleri ve $\mathrm{CO}_{2}$ salınımı azaltılır [3]. Ayrıca absorbsiyonlu soğutma sistemleri dış hava sıcaklığının yüksek olduğu yörelerde ve büyük tesislerde kullanılmaya elverişlidir [4]. Bu avantajları nedeniyle, literatürde güneș enerjisi kaynaklı soğutmayla ilgili birçok çalışma yer almaktadır. Öztürk [5] çalışmasında Mersin ili için güneş enerjisini kaynak olarak kullanarak absorbsiyonlu güç üretme sistemleri ile elektrik üretiminin olup olmayacağını incelemiştir. Sistemde $\mathrm{NH}_{3}-\mathrm{H}_{2} \mathrm{O}$ akışkan çifti ile çalışan teorik bir sistem tasarlayıp termodinamik analiz yapmıştır. Demir vd. [6], çalışmalarında çiftlik tipi bir süt soğutma tankının buhar sıkıştırmalı soğutma sistemiyle soğutulmasına ek olarak $\mathrm{LiCl}-\mathrm{H}_{2} \mathrm{O}$ akışkan çiftiyle çalışan absorbsiyonlu soğutma sistemini ekleyerek, iki sistemin performans ve enerji tüketimini karşılaştırmıştır. Hilali [7], Şanlıurfa ilinde bulunan bir konut için 1sı kazancını, soğutma sistemi elemanlarının değerlerini ve sistemde kullanılan düzlem yüzeyli kollektörün verimini hesaplayarak güneş enerjisi destekli absorbsiyonlu soğutma sistemlerinin verimini incelemiştir. Daşkın ve Aksoy [1], çalışmalarında güneş enerjisi destekli absorbsiyonlu soğutma sistemini kullanarak İnönü Üniversitesi Mühendislik Fakültesi ek binasının soğutulması ve iklimlendirilmesini incelemiştir. $\mathrm{H}_{2} \mathrm{O}-\mathrm{LiBr}$ akışkan çiftinin kullanıldığı sistem için simülasyon yapılarak uygun sistem modellemesi oluşturmuşlardır. Sayadi vd. [8], Tunus şehrinde bir konut için $10 \mathrm{~kW}$ kapasiteli $\mathrm{H}_{2} \mathrm{O}-\mathrm{LiBr}$ akışkan çiftli güneş enerjisi destekli absorbsiyonlu soğutma sisteminin EES ve TRNSYS programlarında simülasyonlarını oluşturarak fizibilitesini ve ekonomik performansını incelemiştir. Kuyumcu vd. [9], güneş enerjisi destekli absorbsiyonlu soğutma sistemi ile Kahramanmaraş ilinde inşa edilmiş bir apartman dairesinin soğutulmasını sağlamışlardır. Kuyumcu vd. [10], Gaziantep ilinde bulunan güneş enerjisi kullanan absorbsiyonlu bir soğutma sistemi ile bir buz pistinin soğutulması üzerine teorik bir çalışma gerçekleştirmişlerdir. Bir diğer çalışmada Şahin vd. [11], Mersin iline ait saatlik atmosfer hava sıcaklığg ve güneş ışınım verilerini kullanarak güneş enerji destekli absorbsiyonlu soğutma (SPAR) sisteminin performans analizini gerçekleştirmişlerdir. Sistemde vakum tüplü güneş kolektörü ve $\mathrm{NH}_{3}-\mathrm{H}_{2} \mathrm{O}$ akışkan çiftini kullanarak güneş enerjili absorbsiyonlu soğutma sistemi tasarlayıp analiz etmişlerdir. Florides vd. [12], Kıbrıs'ta bir konut için TRNSYS programı ile güneş enerjisi destekli soğutma sisteminin simülasyonu oluşturarak fizibilitesini ve ekonomik performansinı incelemiştir.

Güneş haritasının birinci kuşağı olarak adlandırılan bölgede yer alan Mersin İlinde yaz aylarında hava sıcaklığı ve havadaki nem miktarı oldukça fazla olduğundan insanların gereksinim duyduğu konfor şartlarını sağlayabilmek için büyük miktarda enerjiye ihtiyaç duyulmaktadır. Bu ihtiyaç duyulan enerjinin, güneş enerjisi kullanılarak karşılanmasının ülke ekonomisi için büyük avantaj sağlayacağı düşüncesiyle Mersin ili'nde, ana cephesi güney yön olan ve dört cephesi de (Doğu, Bat1, Kuzey, Güney) açık olan 5 katlı bir otelin yaz döneminde soğutma ihtiyacını karşılamak üzere, güneş enerjisi destekli tek etkili su-lityum bromür $\left(\mathrm{H}_{2} \mathrm{O}-\mathrm{LiBr}\right)$ karışımı kullanan absorbsiyonlu bir soğutma makinası tasarlanmış ve teorik olarak analiz edilmiştir. Literatürde Mersin ili için bu tür bir çalışma bulunmadığından dolayı, bu çalışma Mersin ili için yapılacak benzer çalışmalara da ışık tutacaktır.

\section{Materyal ve Metot}

\subsection{Güneş Enerjisi Destekli Absorbsiyonlu Soğutma Sistemi Çalışma Prensibi}

Güneş enerjisi destekli absorbsiyonlu soğutma sistemleri, soğutucu akışkanın basıncını arttırmak için ısı kaynağının güneş olduğu termal bir mekanizmanın kullanıldığı bir tür buhar sıkıştırmalı soğutma sistemleridir. Bu mekanizma termik sıkıştırıcı olarak adlandırılmaktadır ve absorber, sıvı pompası ve jeneratörden oluşmaktadır.

Absorbsiyonlu soğutma sistemlerinde gerçekleşen çevrimde; soğutucu akışkan ve soğutucu akışkan gazını soğuran soğurucu akışkan bulunur. Soğutucu akışkan buharlaştırıcıda buharlaşarak soğutma yükünün ortamdan çekilmesini sağlar. Soğurucu akışkan ise çevrimin belirli kısımlarında soğutucu akışkanı taşır [13]. Absorbsiyonlu soğutma sistemlerinde kullanılacak olan soğutucu-soğurucu çiftlerinin seçimi; kimyasal çözünürlüklerin yüksekliğine, maddelerin kimyasal ve fiziksel özelliklerine 
göre yapılır. Bu çiftlerden en yaygın kullanılanı; soğutucu akışkanın $\mathrm{H}_{2} \mathrm{O}$ (su), soğurucu akışkanın $\mathrm{LiBr}$ (lityum bromür) olduğu $\mathrm{H}_{2} \mathrm{O}-\mathrm{LiBr}$ solüsyonudur [14]. Absorbsiyonlu soğutmada absorban akışkan sıvı, diğer soğutucu akışkan ise absorbe edildiğinde gaz fazındadır. Karışımdaki absorban oranı yüksek soğutucu oranı düşük ise konsantre veya zengin eriyik, absorban oranı düşük soğutucu oranı yüksek ise zayıf eriyik olarak adlandırılır [15]. Güneş enerjisi kaynaklı absorbsiyonlu soğutma sisteminde, güneş enerjisi ile isıtılan sıcak su, sistem elemanlarından jeneratörde $\mathrm{H}_{2} \mathrm{O}-\mathrm{LiBr}$ eriyiğinden soğutucu akışkan olarak kullanılan suyu ayırmak için kullanılır.

Çalışma akışkanının jeneratörde buharlaşarak eriyikten ayrılması için $\mathrm{Q}_{\mathrm{g}}$ jeneratör 1sısı verilir. Böylece soğutucu akışkan buharı eriyikten ayrılır ve soğutucu buharın ayrılmasıyla LiBr bakımından zenginleşen eriyik eşanjörden geçer, fakir eriyiğe 1sı vererek absorbere döner. Buharlaşan akışkan ise kondanserde $\mathrm{Q}_{\mathrm{k}}$ 1sısını vererek sıvı hale geçer. Yüksek basınçta sıvı haldeki soğutucu akışkanının basınc1, genleşme vanası ile düşürülerek evaporatöre gelir ve burada soğutulan ortamdan $Q_{e}$ 1sısını alarak buharlaşır. Akışkan buharı daha sonra absorbere giderek jeneratörden gelen zengin eriyikle birleşir. Bu sırada gerçekleşen işlemde 1sı açığa çıktığı için absorberden $\mathrm{Q}_{\mathrm{a}}$ 1sısı atılmalıdır. Absorberde oluşan fakir eriyik bir sıvı pompası yardımıyla eşanjörden geçirilerek bir miktar 1sı alır ve jeneratöre gönderilir. Çevrim böylece devam eder [16].

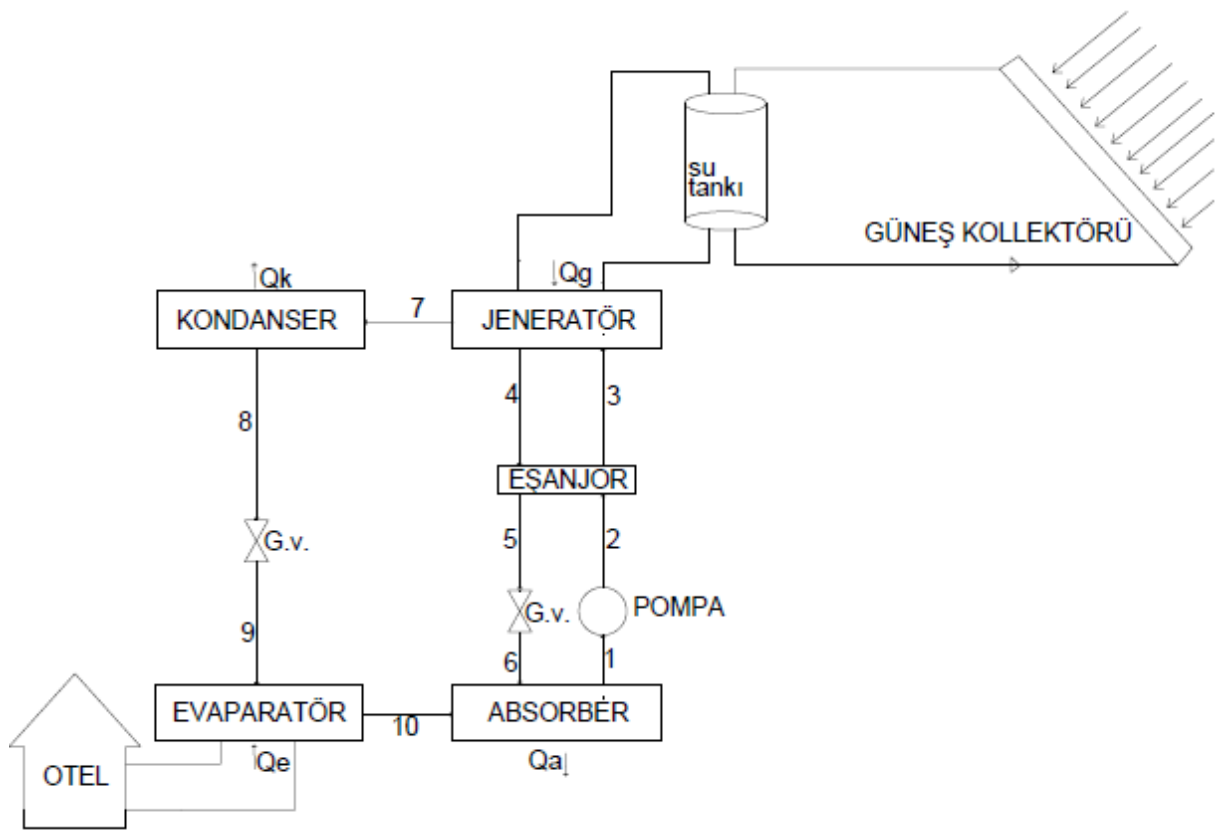

Şekil 1.Güneş enerjisi destekli tek etkili Su-Lityum Bromür $\left(\mathrm{H}_{2} \mathrm{O}-\mathrm{LiBr}\right)$ karışımı kullanan absorbsiyonlu soğutma sisteminin şematik gösterimi

\subsection{Otel İçin Gerekli Toplam Soğutma Yükü}

Mersin ilinde yer alan 5 katlı 40 odalı bir oteli soğutmak için kullanılacak olan güneş enerjisi destekli tek etkili $\mathrm{H}_{2} \mathrm{O}-\mathrm{LiBr}$ çalışma akışkanlı absorbsiyonlu soğutma sistemi tasarımı için öncelikle otelin ihtiyacı olan soğutma yükü belirlenmelidir. Mersin ilinin sahip olduğu iklim gereği, Mayıs-Eylül ayları boyunca soğutma ihtiyacı duyulmaktır. Çalışmanın yapıldığ 1 yalıtımlı otel binasının soğutma yükü, 1981-2010 yılları arasında gerçekleşen ortalama en yüksek sıcaklıklar dikkate alınarak sıcaklıkların en yüksek olduğu Ağustos (Tablo 1) ayı için hesaplanmıştır. 
Tablo 1. Mersin ili için meterolojik veriler [17-18].

\begin{tabular}{|c|c|c|}
\hline AY & ORTALAMA SICAKLIK $\left({ }^{\circ} \mathbf{C}\right)$ & $\mathbf{H}_{\mathbf{Y}}\left(\mathbf{M J} \mathbf{J} \mathbf{m}^{\mathbf{2}}\right.$.gün $)$ \\
\hline Mayis & 21,2 & 26,9 \\
\hline Haziran & 25,0 & 28,6 \\
\hline Temmuz & 27,8 & 27,9 \\
\hline Ağustos & 28,3 & 26,2 \\
\hline Eylül & 25,8 & 21,7 \\
\hline
\end{tabular}

Otel binası 1 zemin ve 4 normal kat olmak üzere 5 kattan oluşmaktadır. Kat planları Şekil 2'de gösterilmektedir. Zemini toprak temaslı, çatı katı düz teras şeklinde olup kat alanı $200 \mathrm{~m}^{2}$ dir. Yapı elemanlarının 1sı geçiş katsayıları dış duvar için $1.03 \mathrm{~W} / \mathrm{m}^{2} \mathrm{~K}$, çift camlı pencere için $2.6 \mathrm{~W} / \mathrm{m}^{2} \mathrm{~K}$, dış kap1 $4.0 \mathrm{~W} / \mathrm{m}^{2} \mathrm{~K}$, döşeme için $0.58 \mathrm{~W} / \mathrm{m}^{2} \mathrm{~K}$ ve tavan için $0.44 \mathrm{~W} / \mathrm{m}^{2} \mathrm{~K}$ 'dir [19]. Otel binasi; iyi izolasyonlu, 1s1 camlı, ana cephesi güney, kuzey, doğu ve batı olmak üzere 4 cepheli ince perde gölgelendirmeli 40 odalı bir binadır. $36,8^{\circ}$ enlem, $34,63^{\circ}$ boylamda bulunan Mersin ili için dış tasarım şartları kapsamında yaz mevsiminde ortam sıcaklığ $35^{\circ} \mathrm{C}$ olarak alınmıştır. Otel mahallerinin konfor sıcaklı̆̆ $25^{\circ} \mathrm{C}$ olacak şekilde Ağustos ayı için soğutma yükü hesaplanmıştır.

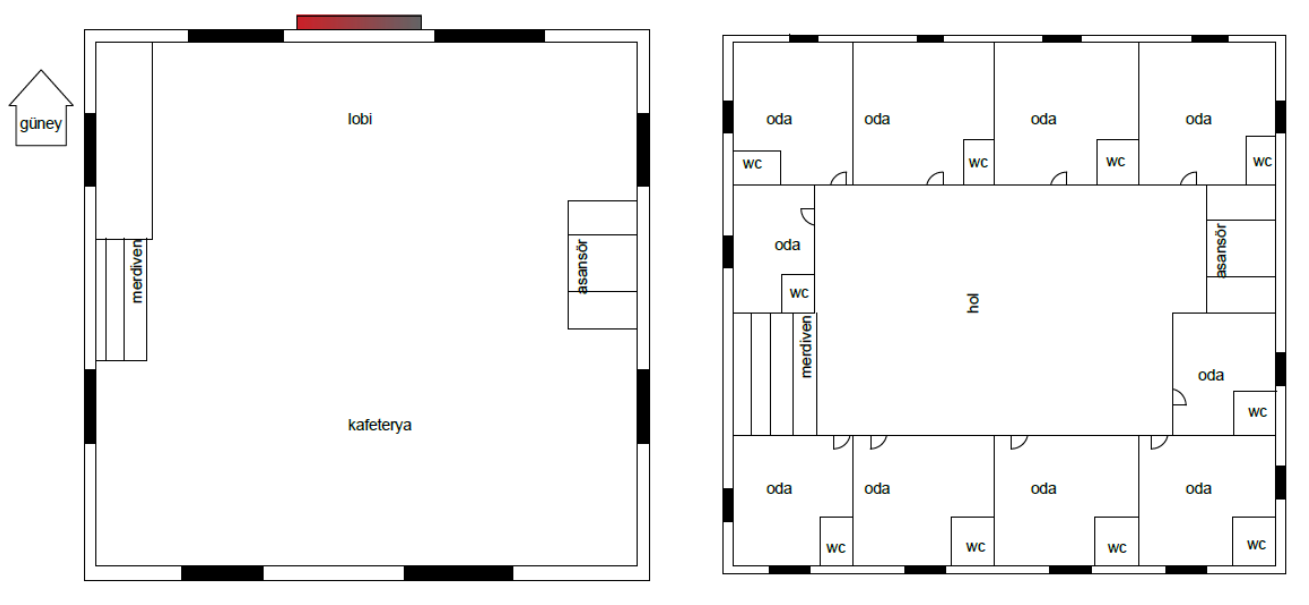

Şekil 2.Otel zemin kat ve normal kat planı

Toplam soğutma yükü hesabı yapılırken; insanlardan gelen 1s1 kazanc1, aydınlatma ve cihazlardan gelen 1sı kazanc1, komşu duvar, döşeme ve tavanlardan gelen 1sı kazanc1, pencereden taşınım ile gelen 1sı kazancı ve pencereden 1şınım ile gelen 1sı kazançları göz önünde bulundurulur. Toplam soğutma yükü aşağıdaki formüller kullanılarak hesaplanır [20];

İnsandan gelen soğutma yükü;

$$
Q_{i}(W)=\text { kişi sayısı } x \text { mahalin özellikleri }(w / k i s ̧ i)
$$

Taze havadan gelen soğutma yükü;

$Q_{T H}(W)=$ kişi başına düşen taze hava miktarl $\left(\mathrm{m}^{3} / \mathrm{h}\right)$ xkişi sayısı $x$ mahal faktörü

Aydınlatma ve elektrikli cihazdan gelen soğutma yükü;

$$
\begin{gathered}
Q_{\text {aydinlatma }}(W)=\text { mahal alanı }\left(\mathrm{m}^{2}\right) \times \text { mahal özellikleri }\left(\mathrm{w} / \mathrm{m}^{2}\right) \\
Q_{\text {elektriklicihaz }}(W)=\operatorname{cihaz} \text { sayısı } \times \text { cihaz özellikleri }(w)
\end{gathered}
$$

Radyasyon ile gelen soğutma yükü;

$$
Q_{\text {radyasyon }}=\text { Pencere özellikleri }\left(w / \mathrm{m}^{2}\right) \times \text { Pencere alanı }\left(\mathrm{m}^{2}\right) \times \text { Pencere gölgelenme faktörü }
$$


Taşınım ve iletim ile gelen soğutma yükü;

$\mathrm{Q}_{\text {taşınım, iletim }}=$ İnsanlar, taze hava, elektrikli cihazlar, aydınlatma ve radyasyonla gelen soğutma yükü miktarı toplamının \%8 ile \%12'si kadardır. Kullanılacak yerin izolasyonuna göre bu yüzde belirlenir.

Toplam soğutma yükü;

$Q_{\text {toplam }}=Q_{\text {insan }}+Q_{\text {tazehava }}+Q_{\text {aydinlatma,elektriklicinaz }}+Q_{\text {radyasyon }}+Q_{\text {tașinım,iletim }}$

denkleminin Mersin ili için düzeltme faktörü 1,24 ile çarpımından elde edilir.

\subsection{Absorbsiyonlu Soğutma Çevriminin Termodinamik Analizi}

Şekil 1'de şematik gösterimi bulunan güneş enerjisi destekli absorbsiyonlu soğutma sistemi tasarımında kullanılan kütle ve enerji denge denklemleri Tablo 2'de verilmiştir. Bu tabloda yer alan; ṁ kütlesel debi, h entalpi, $\dot{Q}_{a}$ absorber 1s1 kapasitesi, $\dot{Q}_{g}$ jeneratör 1s1 kapasitesi, $\dot{Q}_{k}$ kondenser 1s1 kapasitesi, $\dot{Q}_{e}$ evaporatör 1sı kapasitesi ve W pompa işi olarak tanımlanmaktadır. Soğutulması amaçlanan otel için gerekli olan soğutma yükü hesaplanarak evaporatör kapasitesi belirlenmiş olur. Evaporatör kapasitesi ve Tablo 3' de yer alan diğer tasarım parametreleri kullanılarak absorbsiyonlu soğutma sisteminin termodinamik hesapları yapılmıștır.

Tablo 2. Absorbsiyonlu soğutma sisteminin tasarımında kullanılan kütle ve enerji korunum denklemleri [20]

\begin{tabular}{|lll|} 
Sistemin Elemanları & Kütlenin Korunumu & Enerjinin Korunumu \\
\hline Absorber & $\dot{m}_{1}=\dot{m}_{6}+\dot{m}_{10}$ & $\dot{Q}_{a}=\dot{m}_{10} h_{10}+\dot{m}_{6} h_{6}-\dot{m}_{1} h_{1}$ \\
Pompa & $\dot{m}_{1}=\dot{m}_{2}$ & $W_{p}=\dot{m}_{2} h_{2}-\dot{m}_{1} h_{1}$ \\
Eşanjör & $\dot{m}_{2}=\dot{m}_{3}, \dot{m}_{4}=\dot{m}_{5}$ & $\dot{m}_{2}\left(h_{2}-h_{3}\right)=\dot{m}_{4}\left(h_{4}-h_{5}\right)$ \\
Jeneratör & $\dot{m}_{3}=\dot{m}_{4}+\dot{m}_{7}$ & $\dot{Q} g=\dot{m}_{7} h_{7}+\dot{m}_{4} h_{4}-\dot{m}_{3} h_{3}$ \\
Genleşme Valfi 1 & $\dot{m}_{5}=\dot{m}_{6}$ & $h_{5}=h_{6}$ \\
Kondenser & $\dot{m}_{7}=\dot{m}_{8}$ & $\dot{Q}_{k}=\dot{m}_{8} h_{8}-\dot{m}_{7} h_{7}$ \\
Genleşme Valfi 2 & $\dot{m}_{8}=\dot{m}_{9}$ & $h_{8}=h_{9}$ \\
Evaporatör & $\dot{m}_{9}=\dot{m}_{10}$ & $\dot{Q}_{e}=\dot{m}_{10} h_{10}-\dot{m}_{9} h_{9}$ \\
\hline
\end{tabular}

Tablo 3. Absorbsiyonlu soğutma sisteminin tasarım parametreleri

\begin{tabular}{|lcc|}
\multicolumn{1}{c}{ Parametre } & Sembol & Değeri \\
\hline Evaporatör & $\mathrm{Q}_{\mathrm{e}}$ & $84,6 \mathrm{~kW}$ \\
Evaporatör Çıkış Sıcaklığı & $\mathrm{T}_{10}$ & $6{ }^{\circ} \mathrm{C}$ \\
Jeneratör Eriyik Çıkış Sıcaklığı & $\mathrm{T}_{4}$ & $90^{\circ} \mathrm{C}$ \\
Fakir Eriyik Konsantrasyonu & $\mathrm{X}_{1}$ & $\% 55 \mathrm{LiBr}$ \\
Zengin Eriyik Konsantrasyonu & $\mathrm{X}_{6}$ & $\% 60 \mathrm{LiBr}$ \\
Jeneratör Buhar Sıcaklığı & $\mathrm{T}_{7}$ & $85^{\circ} \mathrm{C}$ \\
Eşanjör Çıkış Sıcaklığı & $\mathrm{T}_{3}$ & $65^{\circ} \mathrm{C}$ \\
\hline
\end{tabular}

\subsection{Eğik Kollektör Yüzeyine Gelen Aylık Ortalama Güneş Işınımı ve Kollektör Yüzey Alanının Belirlenmesi}

Soğutma sistemi termodinamik analizleri ile sistemde yer alan jeneratörün ihtiyacı olan 1s1 miktar1 belirlendikten sonra güneş ışınım değerleri dikkate alınarak uygun kollektör yüzey alanı belirlenir. Kolektör yüzey alanı belirlenirken ilk adım denklinasyon açısını hesaplamaktır. Denklinasyon açısı, kollektörlerin yerleştirileceği optimum düzlem eğimini bulmak için kullanılmaktadır. Mersin için aylık ortalama güneş ışınım değerleri $\left(\mathrm{H}_{\mathrm{y}}\right)$ kullanılarak bir gün boyunca eğik düzleme gelen toplam 1şınım miktarı $\left(\mathrm{H}_{\mathrm{t}}\right)$ belirlenir, kollektör cinsine bağlı olarak kollektör verimi hesaplanır ve son olarak böyle bir sistem için gerekli minimum kollektör yüzey alanı belirlenir. İlgili denklemler aşağıda verilmektedir [14]; 
Denklinasyon açısı;

$\delta=23.45^{\circ} \sin \left(360 \frac{n+284}{365}\right)$

Denklemiyle hesaplanır. Bu denklemde $n$ ifadesi yılın kaçıncı günü olduğunu ifade eder. Güneye bakan düzlem eğimi için;

$s_{0}=e-1,5 \delta-\frac{|\delta| e}{180}$

denklemi kullanılır. Denklemdeki e ifadesi enlem açısını ifade etmektedir. Bir gün boyunca eğik düzleme gelen toplam ışııım miktarı olarak tanımlanan $\mathrm{H}_{\mathrm{t}}$;

$\bar{R}=\frac{H_{t}}{H_{y}}$

Denklemi ile hesaplanır. Bu denklemde yer alan $\mathrm{H}_{\mathrm{y}}$, Mersin için aylık ortalama güneş 1şınım değerleridir. Denklemde bulunan $\overline{\mathrm{R}}$ katsayısı güneye dönük düzlemler için;

$\bar{R}=\frac{\cos (e-s) \cdot \cos \delta \cdot \sin H_{g}+\frac{\pi}{180} H g \cdot \sin (e-s) \cdot \sin \delta}{\cos e \cdot \cos \delta \cdot \sin H+\frac{\pi}{180} H \cdot \sin e \cdot \sin \delta}$

eşitliği ile bulunur. Denklemdeki H değeri güneş doğuş/batış açısını göstermektedir;

$H=\arccos (-\tan \delta \tan e)$

denkleminden $\mathrm{H}$ değeri elde edilir. Denklemdeki $\mathrm{H}_{\mathrm{g}}$ değeri;

$H_{g}=\min [\arccos (-\operatorname{tane} \cdot \tan \delta), \arccos (-\tan (e-s) \tan \delta]$

ifadesindeki minimum değer olarak tanımlanır. Aylara göre gün uzunluğu $t_{0}$ ile gösterilmektedir ve aşağıda eşitlik kullanılarak hesaplanır.

$t_{0}($ saat $)=\frac{2}{15} H($ derece $)=\frac{2}{15} \arccos (-$ tan $\delta$ tane $)$

Eğik düzleme düşen günlük ortalama anlık ışınım miktarı $\mathrm{I}_{\mathrm{e}}$ olarak belirtilir ve aşağıdaki eşitlik yardımı ile bulunur.

$I_{e}=\frac{H_{t}}{t_{0}}$

Kullanılması planlanan kollektör yüzey alanının $\left(\mathrm{A}_{c}\right)$ belirlenmesi için aşağıdaki denklem kullanılır. Denklemde kullanılan $Q_{g}$ absorbsiyonlu soğutma makinasının ihtiyacı olan minimum 1sı miktarını, $\eta$ kollektör sisteminin verimini ifade eder.

$A_{c}=\frac{Q_{g}}{\eta I_{e}}$

Kollektör alanı $\left(\mathrm{A}_{c}\right)$ hesaplamak için gerekli olan kollektör verimi, aşağıdaki eşitliklerle ile bulunur.

$\eta=c_{0}-c_{1} \cdot x-c_{2} \cdot x^{2} \cdot I_{e}$

$x=\frac{\Delta T}{I e}$

$\Delta T=T_{\text {ort }}-T_{\mathrm{c}}$

Seçilen kollektörlerden sağlanabilecek faydalı enerji $\left(\mathrm{Q}_{\mathrm{f}}\right)$ aşağıdaki eşitlik ile hesaplanmaktadır.

$Q_{f}=\mathrm{\eta} \cdot A_{c} \cdot I_{e}$

Soğutma sistemlerinin bir kısmı, sistemin ihtiyaç duyduğu 1sının tamamını güneş enerjisinden karşılamak üzere tasarlanırken, bir kısmı da güneş enerjisinin sistem için yeterli olmadığı durumlarda bir yardımcı 1sı kaynağı kullanılacak şekilde tasarlanır [14]. Soğutma sisteminin çalışabilmesi için 
gerekli enerjinin sağlanmasında, güneş enerjisinin kullanım oranı (solar fraksiyon=SF) aşağıdaki denklem ile bulunur.

$S F=1-\frac{Q_{e k}}{Q_{g}}$

Kollektörlerden sağlanabilecek enerji miktarları $\left(\mathrm{Q}_{\mathrm{f}}\right)$, jeneratör için gereken enerji miktarları $\left(\mathrm{Q}_{\mathrm{g}}\right)$ ve aylık gerekli ek enerji miktarı $\left(Q_{\text {ek }}\right)$ kullanılarak SF oranları hesaplanmıştır. Aylık ek enerji miktarı aşağıdaki denklem ile bulunur.

$Q_{e k}=\Delta Q=Q_{f}-Q_{g}$

Ek 1sıtıcı kullanılmayan, sadece güneş enerjisiyle çalışan sistemlerde, güneş enerjisi kullanım oranı (SF) \%100'dür [14].

Sistemleri değerlendirmede sıklıkla kullanılan performans katsayısı (COP) aşağıdaki denklem ile hesaplanır.

$C O P=\frac{Q_{e}}{Q_{g}}$

Güneş enerjisi destekli soğutma sistemi için kollektör alanı belirlenirken, soğutma ihtiyacının olduğu aylar esas alınır ve yıllık soğutma ihtiyacının \%70-80'inin güneş enerjisiyle karşılanmasının ekonomik olduğu göz önünde bulundurulur [22].

\section{Bulgular ve Tartışma}

Bu çalışmada Mersin ilinde yer alan, ana cephesi güney yön olan ve dört cephesi de (Doğu, Batı, Kuzey, Güney) açık olan 5 katlı 40 odalı bir otelin Mayıs-Eylül ayları arasında soğutma ihtiyacını karşılamak üzere, güneş enerjisi destekli tek etkili su-lityum bromür $\left(\mathrm{H}_{2} \mathrm{O}-\mathrm{LiBr}\right)$ karışımı kullanan absorbsiyonlu bir soğutma makinası ve sistem için gerekli 1sıyı karşılayacak güneş kollektörleri tasarlanmış ve teorik olarak analiz edilmiştir. Otel için gerekli soğutma yükü, sıcaklığın en yüksek olduğu Ağustos ayı verilerine göre hesaplanmıştır. Otelin Ağustos ayı için soğutma yükü 84,6 kW olarak belirlenmiştir ve Tablo 4' de soğutma yükü ayrıntıları verilmiştir.

Tablo 4. Soğutma yükü ayrıntıları

\begin{tabular}{|l|c|}
\hline Soğutma Yükü Cinsi & Kapasitesi(W) \\
\hline İnsandan Gelen Soğutma Yükü & 16100 \\
\hline Taze Havadan Gelen Soğutma Yükü & 25200 \\
\hline Elektrikli Cihaz ve Aydınlatmadan Gelen Soğutma Yükü & 29100 \\
\hline Radyasyondan Gelen Soğutma Yükü & 6500 \\
\hline Taşınım ve İletim ile Gelen Soğutma Yükü & 7700 \\
\hline Toplam Soğuma Yükü & 84600 \\
\hline
\end{tabular}

Otelin ihtiyaç duyduğu soğutma yükü, evaporatörde çevreden çekilen ısıya tekabül etmektedir. $\mathrm{Bu}$ noktadan başlayarak Tablo 2'de verilen kütle ve enerji korunum denklemleri kullanılarak absorbsiyonlu soğutma makinasının her bir sistem elemanı için enerji analizi yapılmış ve Tablo 5'de verilmiştir. Bu çalışmada tasarlanan absorbsiyonlu soğutma makinasının soğutma performans katsayısı (COP) 0,71 olarak hesaplanmıştır ve soğutma sistemini oluşturan her bir elemanın kapasiteleri Tablo 6 'da gösterilmiştir. 
Tablo 5. Tek etkili $\mathrm{LiBr}-\mathrm{H}_{2} \mathrm{O}$ absorbsiyonlu soğutma sisteminin termodinamik hesaplama sonuçları

\begin{tabular}{|ccccccc|}
\hline Nokta & $\mathbf{H}(\mathbf{k J} / \mathbf{k g})$ & $\dot{\mathbf{m}}(\mathbf{k g} / \mathbf{s})$ & $\mathbf{P}(\mathbf{k P a})$ & $\mathbf{T}\left({ }^{\circ} \mathbf{C}\right)$ & $\mathbf{X}(\boldsymbol{\%} \mathbf{L i B r})$ & Durum \\
\hline 1 & 83,023 & 0,43644 & 0,934 & 34,9 & 55 & Fakir \\
2 & 83,023 & 0,43644 & 9,662 & 34,9 & 55 & Fakir \\
3 & 145,38 & 0,43644 & 9,662 & 65 & 55 & Fakir \\
4 & 212,191 & 0,40007 & 9,662 & 90 & 60 & Zengin \\
5 & 280,217 & 0,40007 & 9,662 & 54,8 & 60 & Zengin \\
6 & 280,217 & 0,40007 & 0,934 & 44,5 & 60 & Zengin \\
7 & 2627,985 & 0,3728 & 9,662 & 85 & 0 & Kizgin su buhar \\
8 & 185,207 & 0,3728 & 9,662 & 44,3 & 0 & Doymuş su \\
9 & 185,207 & 0,3728 & 0,934 & 6 & 0 & Doymuş su \\
10 & 2511,798 & 0,03637 & 0,934 & 6 & 0 & Doymuş su buharı \\
\hline
\end{tabular}

Tablo 6. Tek etkili $\mathrm{LiBr}-\mathrm{H}_{2} \mathrm{O}$ absorbsiyonlu soğutma sisteminin kapasite sonuçları

\begin{tabular}{|lcc|}
\hline Parametre & Sembol & Değeri \\
\hline Evaporatör Kapasitesi & $\mathrm{Q}_{\mathrm{e}}$ & $84,6 \mathrm{~kW}$ \\
Eriyik pompasında yapılan is & $\mathrm{W}_{\mathrm{ep}}$ & $0,214 \mathrm{~kW}$ \\
Absorber kapasitesi & $\mathrm{Q}_{\mathrm{a}}$ & $10,513 \mathrm{~kW}$ \\
Jeneratör kapasitesi & $\mathrm{Q}_{\mathrm{g}}$ & $119,413 \mathrm{~kW}$ \\
Kondenser kapasitesi & $\mathrm{Q}_{\mathrm{k}}$ & $28,927 \mathrm{~kW}$ \\
Eriyik eşanjör kapasitesi & $\mathrm{Q}_{\mathrm{e}}$ & $27,216 \mathrm{~kW}$ \\
Performans katsayısı & $\mathrm{COP}$ & 0,71 \\
\hline
\end{tabular}

Tasarlanan absorbsiyonlu soğutma sisteminde bulunan jeneratörün ihtiyacı olan minimum 1S1 miktarı $\left(Q_{g}\right)$, termodinamik analizlerle $119.413 \mathrm{~kW}$ olarak hesaplanmıştır. Kollektörlerin yerleştirileceği optimum düzlem eğimi $16.33^{\circ}$ olarak belirlenmiştir. Mersin için aylık ortalama güneş 1şınım değerleri $\left(\mathrm{H}_{\mathrm{y}}\right)$ kullanılarak eğik düzleme bir gün boyunca gelen toplam 1şınım miktarı $\left(\mathrm{H}_{\mathrm{t}}\right)$, aylara göre gün uzunlukları $\left(\mathrm{t}_{0}\right)$ ve eğik düzleme gelen güneş 1şınım miktarı $\left(\mathrm{I}_{\mathrm{e}}\right)$ Tablo 7 ' de gösterilmiştir.

Tablo 7. Mersin ili için 16,33lik eğik düzleme düşen aylık ortalama 1şınım değerleri, gün uzunluğu ve eğik düzleme düşen günlük ortalama anlık 1şınım değerleri

\begin{tabular}{|c|c|c|c|}
\hline $\mathbf{A y}$ & $\mathbf{H}_{\mathbf{t}}\left(\mathbf{M J} / \mathbf{m}^{2}\right.$.gün $)$ & $\mathbf{t}_{\mathbf{o}}(\mathbf{h})$ & $\mathbf{I}_{\mathbf{e}}\left(\mathbf{W} / \mathbf{m}^{\mathbf{2}}\right)$ \\
\hline Mayıs & 26,72 & 13,97 & 531,30 \\
\hline Haziran & 28,32 & 14,45 & 544,41 \\
\hline Temmuz & 27,62 & 14,21 & 539,92 \\
\hline Ağustos & 25,94 & 13,34 & 540,15 \\
\hline Eylül & 21,48 & 12,22 & 488,28 \\
\hline
\end{tabular}

Tablo 8'de kolektör verimi (ఇ), güneş enerjisinin kullanım oranı (SF) ve jeneratörün ihtiyacı olan minimum ısı miktarına $\left(Q_{g}\right)$, eğik düzleme gelen güneş 1şınım miktarı $\left(I_{e}\right)$ ve kollektör verimine bağlı olarak hesaplanan minimum kollektör yüzey alanı değerleri verilmiştir. Sonuçlar incelendiğinde vakum tüplü kollektör kullanılması halinde, düz plakalı kollektöre kıyasla daha verimli, daha yüksek güneş enerjisi kullanım oranına sahip ve sistemin $330,6 \mathrm{~m}^{2}$ daha az kollektöre ihtiyaç duyulduğu anlaşılmaktadır.

Tablo 8. Sistemde kullanılması planlanan kollektör cinsleri

\begin{tabular}{|c|c|c|c|}
\hline Kollektör cinsi & $n$ & $\mathbf{S F}$ & $\operatorname{Alan}\left(m^{2}\right)$ \\
\hline $\begin{array}{c}\text { Viessmann Vitesol300T Vakum Tüplü } \\
\text { Kollektör } \\
\text { Optik verim:0,809 } \\
\mathrm{k}_{1}: 1,37 \mathrm{~W} / \mathrm{m}^{2} \mathrm{~K} \\
\mathrm{k}_{2}: 0,0068 \mathrm{~W} / \mathrm{m}^{2} \mathrm{~K} \\
\end{array}$ & 0,615 & 1 & 359,5 \\
\hline $\begin{array}{c}\text { Viessmann Vitesol300F Düzlemsel } \\
\text { Kollektör } \\
\text { Optik verim: } 0,834 \\
\mathrm{k}_{1}: 3,66 \mathrm{~W} / \mathrm{m}^{2} \mathrm{~K} \\
\mathrm{k}_{2}: 0,0169 \mathrm{~W} / \mathrm{m}^{2} \mathrm{~K}\end{array}$ & 0,320 & 0,874 & 690,1 \\
\hline
\end{tabular}




\section{Sonuç ve Öneriler}

Bu çalışmada Mersin İlinde bulunan 40 odalı bir otelin soğutma işlemi için güneş enerjisi destekli tek etkili su-lityum bromür $\left(\mathrm{H}_{2} \mathrm{O}-\mathrm{LiBr}\right)$ karışımı kullanan absorbsiyonlu bir soğutma sistemi tasarlanmış ve teorik olarak analizler yapılmıştır. Otelin Ağustos ayı için toplam soğutma yükü 84,6 kW olarak hesaplanmış ve bu soğutma yükünü sağlamak için jeneratöre verilmesi gereken 1 sının ise $119.413 \mathrm{~kW}$ olduğu belirlenmiştir. Güneşten bu ısının karşılanması için, \%61.5 verime sahip $359.5 \mathrm{~m}^{2}$ vakum tüplü kolektör kullanılması gerektiği anlaşılmıştır. Tasarlanan bu absorbsiyonlu soğutma makinesinin ihtiyaç duyduğu ısının kollektörden sağlanamadığı durumlarda, elektrik enerjisi veya doğal gaz ile çalışan boyler kullanılması bir çözüm olacaktır.

\section{Kaynaklar}

[1] Daşkın M., Aksoy İ.G. 2014. İklimlendirme Amaçlı Güneş Enerjisi Destekli Bir Absorbsiyonlu Soğutma Sisteminin Simülasyonu, Batman Üniversitesi Yaşam Bilimleri Dergisi, 4 (1): 52-65.

[2] Dinçer İ., Erdallı Y. 1993. Absorbsiyonlu Soğutma Sistemlerinin Rolü ve Etkinliği, Termodinamik Dergisi, 5: 31-37.

[3] Büyükalaca O., Yılmaz T. 2003. Güneş Enerjisi ile Soğutma Teknolojilerine Genel Bir Bakış, Tesisat Mühendisliği Dergisi, Mayıs-Haziran, 3: 45-56.

[4] Pastakkaya B., Ünlü K., Yamankaradeniz R. 2008. Isıtma ve Soğutma Uygulamalarında Güneş Enerjisi Kaynakl1 Absorbsiyonlu Sistemler, TTMD Dergisi, 57: 25-32.

[5] Öztürk İ.T. 2006. Güneş Enerjisinden Absorbsiyon Teknolojisi Yardımı ile Güç Üretimi, Mühendis ve Makine, 563 (47): 17-23.

[6] Demir V., Günhan T., Şahin Şencan A., Ekren O., Bilgen H., Erek A. 2016. Süt Soğutma Tankının Buhar Sıkıştırmalı ve Güneş Enerjili Absorbsiyonlu ( $\left.\mathrm{LiCl}-\mathrm{H}_{2} \mathrm{O}\right)$ Soğutma Sistemleriyle Soğutma Performansının Deneysel İncelenmesi, Gazi Üniversitesi Mühendislik Mimarlık Fakültesi Dergisi, 31 (1): 29-37.

[7] Hilali İ. 1995. Güneş Enerjisi Destekli Absorbsiyonlu Soğutma Sisteminin Şanlıurfa İlinde Bir Konuta Uygulanması, Harran Üniversitesi, Fen Bilimleri Enstitüsü, Makine Mühendisliği Anabilim Dalı, Yüksek Lisans Tezi, 54s. Şanlıurfa.

[8] Sayadi Z., Bourois M., Bellagi A. 2013. Technical and Economic Analysis of a Solar-AssistedAirconditioningAystem, Int. J. Renewable Energy Technology,4 (1):65-85.

[9] Kuyumcu M.E., Şahin H.E., Yumrutaş R., İmal M. 2015. Kahramanmaraş Kentinde Güneş Enerjisi Destekli Absorbsiyonlu Soğutma Sistemi Kullanılarak Bir Apartman Dairesinin Soğutulması, KSU Mühendislik Dergisi, 18 (2): 25-32.

[10] Kuyumcu M.E., Şahin H.E., Yumrutaş R. 2015.Güneş Enerjisi Destekli Absorbsiyonlu Soğutma Sistemi ile Buz Pistinin Soğutulmasının Teorik İncelenmesi, TTMD Isıtma, Soğutma, Havalandırma, Klima, Yangın ve Sihhi Tesisat Dergisi, 96: 24-31.

[11] Şahin B., Bilgili M., Çetingöz A., Kurtulmuş N. 2016. Performance Analysis of Solar Powered AbsorptionRefrigerationSystemfor Mersin Province, Çukurova Üniversitesi Mühendislik Mimarlık Fakültesi Dergisi, Adana, 31 (1): 371-379.

[12] Florides, G.A.,Kalogirou, S.A., Tassou, S.A., Wrobel, L.C. 2002. Modelling, Simulation of an Absorption Solar CoolingSystem of Cyprus, Solar Energy,72: 43-51.

[13] Yamankaradeniz R., Horuz İ., Coşkun S. 2002. Soğutma Tekniği ve Uygulamaları, Vipaş A.Ş., 608s. Bursa.

[14] Goralı E. 2007. Güneş Enerjili Absorbsiyonlu Soğutma Sistemi, İstanbul Teknik Üniversitesi, Enerji Enstitüsü, Yüksek Lisans Tezi, 70s. İstanbul.

[15] Yalçın E., Kavaklı A. 2010. Absorbsiyonlu Soğutma Sistemleri ile Egzoz Gazı Atık Isısından Faydalanarak Otobüs Kliması Sistemleri için Kaynatıcı Tasarımı, BAÜ FBE Dergisi, 12 (1): 136152.

[16] Yakut A.K., Şahin Şencan A., Selbaş R., Dikmen E., Görgülü B., Dostuçok İ., Kutlu S. 2013. Güneş Enerjisi Destekli Absorbsiyonlu Soğutma Sisteminin Termodinamik İncelenmesi, Soğutma Dünyas1, Ocak-Şubat-Mart, 16 (60): 76-81.

[17] MGM.2018. https://www.mgm.gov.tr/?il=Mersin, (Erişim Tarihi: 25.04.2018).

[18] YEGM. 2018. http://www.yegm.gov.tr/MyCalculator/pages/33.aspx, (Erişim Tarihi: 25.04.2018). 
[19] Kent E.F., Kaptan İ.N. 2009. İzmir İlindeki Elli Yataklı Bir Otel için Güneş Enerjisi Destekli Isıtma ve Absorbsiyonlu Soğutma Sisteminin Teorik İncelenmesi, IX. Ulusal Tesisat Mühendisliği Kongresi, 06-09 Mayıs, 163-170, İzmir.

[20] Canovate enerji. 2018. http://portal.canovateenerji.com/trTR/sogutma-yuku-hesabi/ (Erişim Tarihi:25.04.2018).

[21] Yalçın R.Ç. 2012. Bir Absorbsiyonlu Soğutma Sisteminin Isıl Analizi ve Tasarımı, Dokuz Eylül Üniversitesi, Makine Mühendisliği Bölümü, Termodinamik Anabilim Dalı, Yüksek Lisans Tezi, $77 \mathrm{~s}$. İzmir.

[22] Henning H.M. 2004. Solar-AssistedAir-Conditioning in Buildings, Springer Press, Viyana. 